value of the Glasgow fellowship will be $£ 750$ per annum and is also intended for research, usually at Ph.D. level. The trustees will also consider at the same time applications for one Ramsay Travel Grant, not exceeding $£ 350$ for the year 1967-68. The grant will be limited to junior academic chemistry staff of universities and colleges of technology or advanced technology in Scotland. Further information about both these awards can be obtained from the Joint Honorary Secretaries, Ramsay Memorial Fellowships Trust, University College, Gower Street, London, W.C.1.

IN an advertisement which appeared in Nature on October 15 the Anna Monika Foundation announced the award of three prizes for research into the physical causes and functional disturbances in endogenous depression. By an error of the Foundation's, the address to which applications should be sent was given as Peter Rehme, 46 Dortmung, Tollnerstrasse 9-11 and not, as it should have been, 46 Dortmund, Tollnerstrasse 9-11.

The Society for Chemical Industry has set up a Solvent Extraction Group and will be holding an inaugural meeting at its headquarters, 14 Belgrave Square, London, S.W.1, on October 28, 1966. Proceedings will start at 9.30 in the morning.

A conference on "Meteorite Research in the United Kingdom" will be held on December 15, 1966, at the University of Leicester. Participation is limited to people in Britain at present working in this field. Further information can be obtained from A. J. Meadows, Department of Astronomy, University of Leicester.

A CONFRONTAtion between mathematicians and physicists is planned for the period July 16 to August 31, 1967, at the Battelle Seattle Center of the Battelle Memorial Institute. Some thirty people, half of them physicists and half mathematicians, will be given an opportunity to exchange views, usually informally, on topics such as differential geometry, topology, relativity and Feynman graphs. Participants must be prepared to stay the whole of six weeks, will be paid $\$ 8$ a day subsistence and also provided with living accommodation. "Limited assistance towards travel expenses will be available on justification of need." The organizers of the gathering, which is described as the first "Summer Rencontres in Mathematics and Physics", are Professors C. M. DeWitt (North Carolina) and J. A. Wheeler (Princeton). Applications should be sent to Prof. DeWitt not later than February $22,1967$.

A NEW journal entitled International Journal of Quantum Chemistry is to be published by the Interscience Division of John Wiley and Sons early in 1967.
A JorNT symposium on "Rheology and Texture of Foodstuffs", arranged by the Society of Chemical Industry Food Group and the British Society of Rheology, will be held at the School of Pharmacy, University of London, during January 5-6. Further information can be obtained from P. Sherman, Unilever Research Laboratory, Welwyn, Herts.

The fourth Caribbean Chemical Symposium will be held in the University of the West Indies during January 3-7. Sessions of the symposium, which is intended primarily for chemists from countries in the Caribbean area, will be arranged in two sections-Physics and Inorganic Chemistry, and Organic Chemistry and Biochemistry. Further information can be obtained from the Organizing Secretary, Chemistry Department, University of the West Indies, Mona, Kingston 7.

The 1967 Texas Symposium on "Relativistic Astrophysics" will be held in New York during January 23-27. Among the topics discussed will be quasi-stellar sources, "fireball physics", X-ray and $\gamma$-ray astronomy, cosmic neutrinos, and observational cosmology. Further information can be obtained from Prof. A. G. W. Cameron, Belfer Graduate School of Science, Yeshiva University, Amsterdam Avenue and 186th Street, New York, New York 10033.

A conference on "Solid State Physies" will be held by the Institute of Physics and the Physical Society in the University of Manchester during January 4-7. This conference will follow the same general pattern as the meetings hold in Bristol and Manchester in preceding years, and will provide an opportunity for workers in all branches of solid state physics to meet and discuss recent developments. Further information can be obtained from the Meetings Officer, The Institute of Physics and the Physical Society, 47 Belgrave Square, London, S.W.1.

Erratum. In the article entitled "Photosynthetic Nitrite Reductase and the Significance of Hydroxylamine in Nitrite Reduction in Plants" by Dr. G. F. Betts and Dr. E. J. Hewitt, which appeared on p. 1327 of the June 25, 1966, issue of Nature, in line 9 of the paragraph on p. 1327 beginning "Using rate limiting ratios . . ." $10^{-15} \mathrm{M}$ should read $10^{-5}$ M. Also the last line of the first paragraph should read " . . . with fungi, ${ }^{6,7}$ ", and not ". . . with fungi ${ }^{5,7}$, .

Corrigendum. In the article entitled "Osmotic Emergency Purifier of Sea Water" by K. Popper, W. M. Camirand, Dr. W. L. Stanley and F. S. Nury, which appeared on p. 297 of the July 16, 1966, issue of Nature, the thicknesses 88 and 120 mils should read 0.88 and $1 \cdot 20$ mils throughout.

\title{
The Night SKy in NOVember
}

All times are in Universal Time

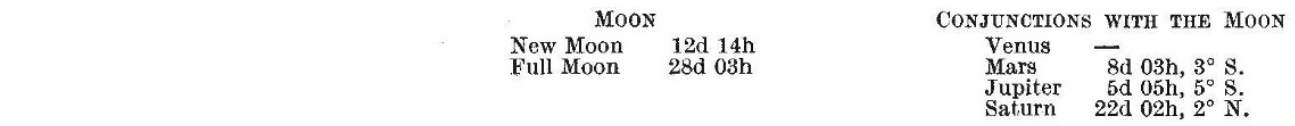

\begin{tabular}{|c|c|c|c|c|c|c|c|}
\hline \multicolumn{8}{|c|}{ Times of rising $(R)$ and setting $(S)$ during the month } \\
\hline Name & $R / S$ & Beginning & Middle & End & Mag. & $D_{g}\left(10^{6}\right.$ miles $)$ & Zodiacal position \\
\hline Mercury & $R$ & Unfavoura & servation & $5 \mathrm{~h} 45 \mathrm{~m}$ & +0.6 & 63 & Libra \\
\hline Venus & - & Unfavoura & servation & & - & 159 & Libra \\
\hline Mars & $\boldsymbol{R}$ & 1h $25 \mathrm{~m}$ & in $15 \mathrm{~m}$ & 1h $05 \mathrm{~m}$ & $+1 \cdot 6$ & 173 & Leo \\
\hline Jupiter & $R$ & $21 \mathrm{~h} 50 \mathrm{~m}$ & $20 \mathrm{~h} 55 \mathrm{~m}$ & $19 \mathrm{~h} 50 \mathrm{~m}$ & -1.9 & 451 & Cancer \\
\hline Saturn & $S$ & $2 \mathrm{~h} 35 \mathrm{~m}$ & 1h $35 \mathrm{~m}$ & Oh $35 \mathrm{~m}$ & $+1 \cdot 2$ & 837 & Aquarius \\
\hline
\end{tabular}

$\begin{array}{ccc}\text { METEORS } & \text { Active period } & \text { Date of maximum } \\ \text { Name } & \text { Oct } 26 \mathrm{~d}-\text { Nov } 16 \mathrm{~d} & 1 \mathrm{~d}-10 \mathrm{~d} \\ \text { Taurids } & 14 \mathrm{~d}-18 \mathrm{~d} & 16 \mathrm{~d}-17 \mathrm{~d}\end{array}$

Other Phenomena

$12 d$

Total Eclipse of Sun:

Eclipse begins

Central Eclinse begins

Central Eclipse at local apparent Moon

Central Eclipse ends

Eclipse ends
Radiant

54. $4^{\circ}$ R.A., $+14^{\circ}$ Dec.
Remarks

Favourable at later dates Favourable 